\title{
Vascular anatomic considerations in lateral sinus thrombosis
}

Volume 9 Issue $3-2017$

\section{Introduction}

There are several categorizations for infectious complications for Acute Middle Ear Infection and Chronic Middle Ear Infection. We adopted the categorization that splits intra-temporal and extratemporal complications, and for extra-temporal we make a difference between intra-cranial and extra-cranial.

Diagnosis and treatment of middle ear infections have improved in the past few years due to technological advances in imagenology, early diagnosis and multi-disciplinary approaches, and although the incidence of complications in infectious processes of the ear has gone down drastically due to vaccination and use of antibiotics, we still encounter complications with varied frequencies according to the different studies available.

Intra-cranial complications can be generated by chronic and acute ear pathologies. These can be produced by closeness, continuity, trans-labyrinthic or blood transmission, depending on factors such as the particular germ strength, the patient immunological status and anatomical predispositions.

Intra-cranial complications usually evolve in a continuous pattern, starting with meningeal irritation and suppurated collections and finally progressing to cerebritis and cerebral or cerebellal abcess. In evolved cases it's normal to find thrombosis of the sinus durae matris starting in the lateral sinus that can advance into the other sinus durae matris generate thrombosis of the internal jugular vein. ${ }^{1}$

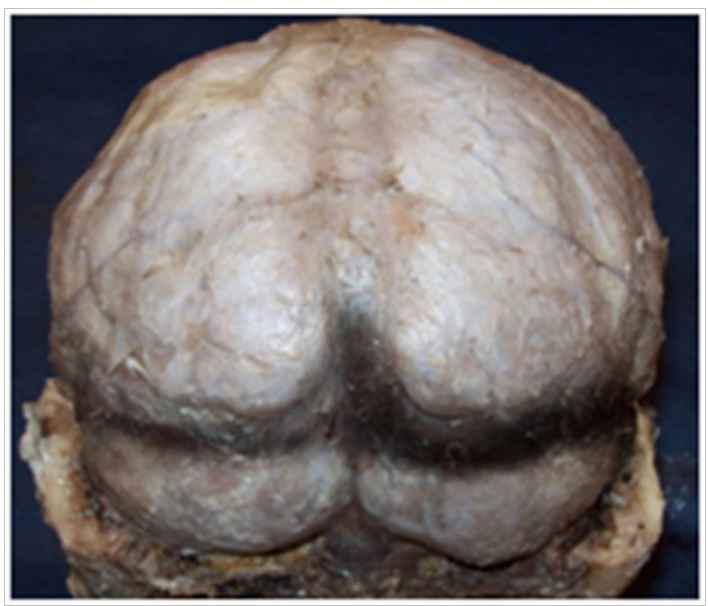

Figure I Cadaveric dissection. Posterior view of the head without the cranial vault showing dura mater in supra and infra tentorial floors and the origin of the lateral sinuses at the level of the confluence sinnum (Prensa de Herofilo).

We will focus specifically in one of the intra-cranial complications, the lateral sinus thrombosis. To understand the etiopathogenesis of the lateral sinus thrombosis in the context of an otomastoiditis we first need to understand the behavior of the intra-cranial venous drainage and the Mastoid veins.

\author{
Gabriel Charlone Granucci, Florencia \\ Romero Lema, Andres Saibene \\ Otorrinolaringólogo, Asistente, Hospital de Clínicas, Montevideo, \\ Uruguay
}

Correspondence: Gabriel Charlone, Otorrinolaringólogo, Asistente, Hospital de Clínicas, Montevideo, Uruguay, Email gabriel.charlone@gmail.com

Received: April 28, 2017| Published: December 05, 2017

For this we used cadaveric dissection of adults preserved in Montevideo Solution (4\% formaldehyde solution). The cranial vault was removed with Stryker saw and the posterior fossa was discovered resecting the posterior sector of the occipital bone to the foramen magnum (Figure 1). The mastoid is then drilled to reveal the lateral sinus (Figure 2).

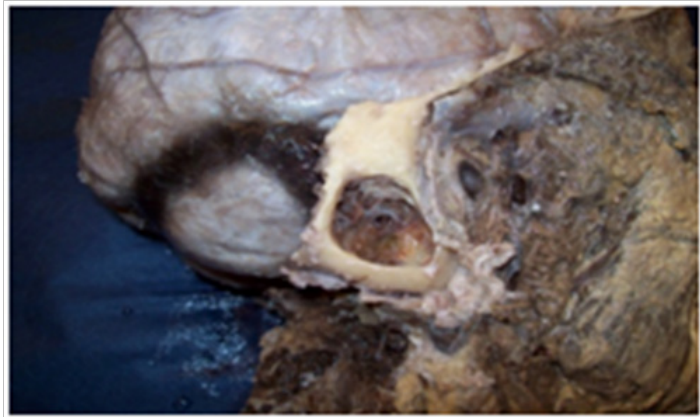

Figure 2 Cadaverous dissection, lateral view showing sigmoid section of the lateral sinus in a mastoidectomy.

We can divide the intra-cranial venous drainage in three components, the deep veins, the superficial veins of the brain and the dural venous sinuses; these structures are exclusive to the encephalon. The whole system is designed so that the venous blood coming from the encephalon drains into the prensa de Herofilo (Confluence Sinnum) at the internal occipital protuberance in the posterior section of the cerebellar tentorium (Figure 1).

This is the place where the lateral sinuses originate and these last estructure, related to the deep side of the mastoid bone, are called sigmoid sinuses. When the sigmoid sinus reaches the medial section of the jugular foramen it turns into the internal jugular vein, which is the only venous drainage for the encephalon..$^{2,3}$

The sigmoid section of the lateral sinus is the terminus for the mastoid emissary vein, whose drainage area includes the mucoperiosteum of the mastoid cells and the mastoid region skin 
appendages (Figure 2). This explains the septic thrombosis of the lateral sinus due to septic thrombus in the emissary vein during infectious processes of the mastoid (Figure $3 \& 4$ ). ${ }^{2-4}$
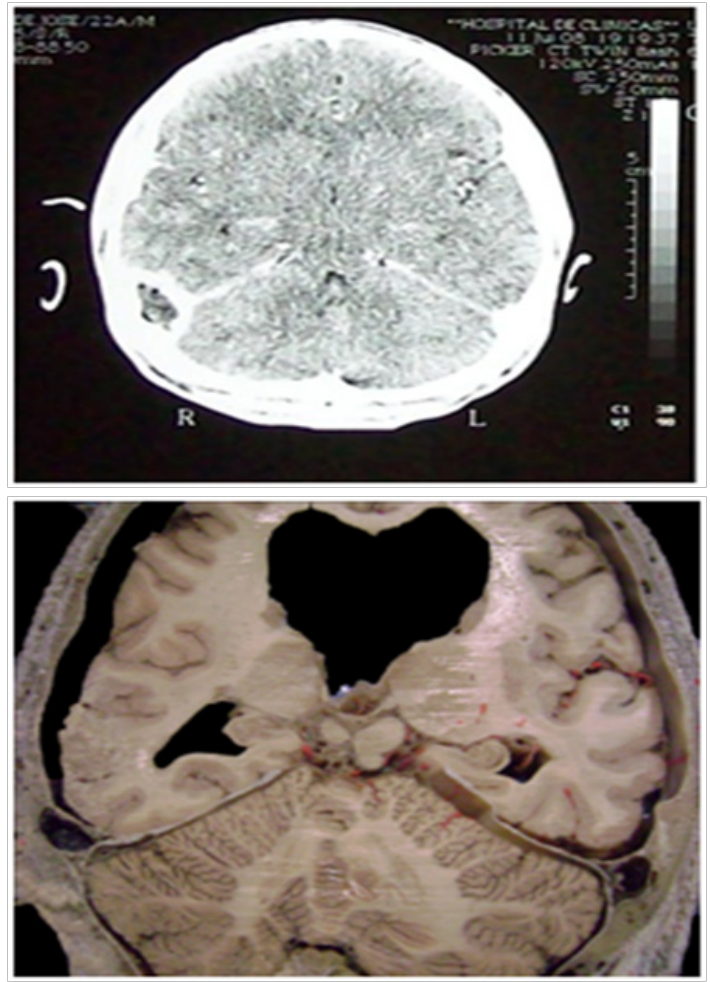

Figure 3 \& 4 Right lateral sinus thrombosis in sigmoid section. Anatomic imaging correlation.

\section{Conclusion}

Septic thrombi coming from the mastoid emissary vein are the key ethopatogenic mechanism in lateral sinus thrombosis derivated from otomastoiditis, noting that the mastoid emissary vein is the only vein draining to the dural system in the lateral sinus.

\section{Acknowledgments}

None.

\section{Conflicts of interest}

Author declatres there are no conflicts of interest.

\section{Funding}

None.

\section{References}

1. Robert FS, Shaun CD, Vivek RD, et al. Vascular Considerations in Neurotologic Surgery. In: Derald EB, et al. (Eds.), Otologic Surgery. ( $3^{\text {rd }}$ edn), Saunders Elsevier, USA. 2010. p.799-813.

2. Michel L, Alfredo L. Vascularización del encéfalo. Colección Latarjet. Anatomía Humana. (4 ${ }^{\text {th }}$ edn), Panamericana, USA. 2004. p.254-259.

3. Michel L, Alfredo RL. Meninges Craneanas. Colección Latarjet. Anatomía Humana. (4th edn), Panamericana, USA. 2004. p.223-230.

4. Rebollo MA, Víctor RS. Circulación encefálica. Neuroanatomía. InterMedica Editorial. 1988. p.515-521. 